\title{
Double-Level Indication of Globalization Effects in Portfolio Investment Models
}

\author{
Valeriy V. Davnis, Viktoriya I. Tinyakova, Valeriy A. Fetisov, Marina A. Chervontseva, Svetlana \\ I. Oparina
}

\begin{abstract}
In well-known reasons, the question of influence of globalization on decisions in the theory of portfolio investment was not discussed, since this was not necessary. The relevance of such a research became actual after the appearance of "young" financial markets only, where the processes of profitability formation of financial assets depended on globalization. In this article, to study this problem, proposed a model that describes a double-level mechanism for profit generating. Usage of this model allowed us to set the specificity of the influence of globalization to the main characteristics of portfolio decisions. Based on this specificity was modified the Sharp's diagonal portfolio investment model with the aim of its practical use in the context of globalization. The performed calculations confirmed the validity of the theoretical recommendations.
\end{abstract}

Keywords : securities portfolio, globalization effects, stock indices, modeling of profitability, major components, double-level model of the assets return.

\section{INTRODUCTION}

At the time of origin of the portfolio investing theory, the effects of globalization were not so noticeable, so that they could be significantly indicated in created theory (A.N. Burenin, 2008). Moreover, the hypothesis "everything is included into the price of an asset", which dominates in determination of the interaction of market processes, did not focus on the search for factors that specify the mechanism of price assessment. This understanding was realized in the first model of portfolio investment proposed by $\mathrm{H}$. Markowitz (1952) and was supported for a long time by the authors (J. Lintner (1965), R. Roll (1977), J. Tobin (1958, 1965). Portfolio theory was developed in the works of V.V. Davnis, M.A. Ziroyan \& V.I. Tinyakova (2017), V.V. Davnis, M.A. Ziroyan, M.V. Vladyka, E.N. Kamyshanchenko \&V.I. Tinyakova (2015), L.P. Yanovsky \& S.N. Vladykin (2009), V.I. Shiryaev (2009).

The first person, who provided for the reflection of the mechanisms of formation of the profitability of a financial asset in his model was W. Sharp (1963, 1964, 1970). To build his diagonal portfolio investment model, he used the

Revised Manuscript Received on October 15, 2019.

* Correspondence Author

Valeriy V. Davnis, Belgorod State University (Pobedy Str. 85, 208000 Belgorod, Russia),

Viktoriya I. Tinyakova, Belgorod State University (Pobedy Str. 85, 208000 Belgorod, Russia),

Valeriy A. Fetisov, Belgorod State University (Pobedy Str. 85, 208000 Belgorod, Russia),

Marina A. Chervontseva, Belgorod State University (Pobedy Str. 85, 208000 Belgorod, Russia),

Svetlana I. Oparina, Moscow Metropolitan Governance University (Sretenka Str., 28, 107045, Moscow, Russia).

econometric analog of CAPM, which reproduced the linear dependence of the asset's return on the index. The econometric approach allowed Sharp to significantly expand the possibilities of investment analysis. Risk gained a structured view. It succeeded in isolating the systematic component generated by the market and the component that reflected the asset's own risk. This allowed us to get a new vision of the mechanisms and methods of forming portfolio decisions, but the issue of the impact of globalization on the formation of portfolio decisions was not considered. The current situation with exploration of this problem requires clarification.

The relevance of indication of the globalization effects in portfolio investment models matured to a level that could be identified in the adequacy of the regression dependencies of returns on factors associated with globalization. The plotting of such regression dependencies became necessary and practically possible only after the emergence of young financial markets such as, for example, the Russian market. Currently, all processes of profitability formation in such markets, without exception, depend on the effects of globalization, generated mainly by the financial markets of the West (I.A. Balyuk and others (2018), V.I. Tinyakova, A.N. Maloletko, O.V. Kaurova, M.V. Vinogradova \& A.A. Larionova (2017), T.V. Karyagina, M.V. Lebedeva, V.A. Fetisov (2015), V.V. Demidov (2007)).

Without a doubt, from the above reasoning it follows that the relevance of indicating of the globalization effects is matured. But it's arises the question regarding the apparatus, with which you can take into account the effects of globalization while making of investment decisions. The answer to this question is a double-level model for the organization of the profitability of financial assets, which implements the mechanism according to which globalization affects the profitability of financial assets through the national market. The details of plotting and analyzing of portfolio decisions using this model are described below.

\section{Double-level model of the assets return}

Sharp's diagonal model remains the basic model for forming of portfolio of investments in the context of globalization.

$$
\begin{array}{r}
\boldsymbol{w}_{n+1}^{\prime} \mathbf{z}_{d} \boldsymbol{w}_{n+1} \rightarrow \min , \\
\boldsymbol{w}_{n+1}^{\prime} \boldsymbol{\alpha}=\mu, \\
\boldsymbol{w}^{\prime} \boldsymbol{i}=1, \\
\boldsymbol{w}^{\prime} \boldsymbol{\beta}=w_{n+1},
\end{array}
$$

где 
$\mathbf{\Sigma}_{\mathbb{d}}-$ extended version of the diagonal matrix of residual dispersions;

$\boldsymbol{w}_{n+1}^{\prime}$-extended vector from portfolio components;

$w^{b}$-is a vector, which sets portfolio structure;

$\alpha-$ is an intersection of the regression equation;

$\beta$-is a regression coefficient;

$i$-is a vector of units.

If the portfolio solution is plotted taking into account the conditions of globalization and the Sharpe model is used for this, than arises the question: how and on what model basis needs to be modified in order for the plan to be realized. In the case of focusing on the synergistic effect of globalization, providing for the possibility of describing the interaction of global markets using the main components, the problem could be solved by using regressions on the main components. In fact, this simplifies the idea of the mechanism by which globalization influences the formation of optimal portfolio decisions. Without giving up the idea of describing globalization using the main components (V.V. Davnis, S.E. Kasatkin, A.A. Ardakov (2012), V.I. Tinyakova \& E.V. Miroshnikov (2019)), we propose to use two-level model that explains the more complex mechanism of the impact of globalization on investment decisions.

It is known that Sharp used to build his diagonal model, the numerical characteristics of a one-factor regression model. Therefore, first of all, in order to determine the possibilities of applying the double-level model to the construction of a modified version of the Sharp diagonal model, it is necessary to analyze the numerical characteristics of this model and understand how they can be used to modify the diagonal model. Formally, double-level is written as follows

$$
\begin{aligned}
& r_{I}=\alpha_{g}+\beta_{g} r_{g}+\varepsilon_{g} \\
& r_{i}=\alpha_{i}+\beta_{i} r_{I}+\varepsilon_{i}
\end{aligned}
$$

where

$$
r_{I}-\text { is a profitability of the national market, described }
$$

by the profitability of the index;

$$
r_{g}-\text { is the average profitability of foreign markets, }
$$

described by the off-center main component of the indices;

$$
\begin{aligned}
& r_{i}-\text { is a return of the } i-\text { th asset; } \\
& \alpha_{g}, \beta_{g} \text { - are coefficients of the regression equation }
\end{aligned}
$$

describing the influence of the effects of globalization on the profitability of the national market;

$\alpha_{i}, \beta_{i}-$ are coefficients of the regression equation describing the effect of the average yield of the national market on the yield of the $i$-th asset;

$$
\varepsilon_{g}-\text { is an unobservable random unit, which }
$$

characterizes that part of the change in the yield of the national market that is not explained by the corresponding changes in the global market;

$$
\varepsilon_{i} \text { - unobservable random unit, which characterizes }
$$

that part of the change in the yield of the $i$-th asset that is not explained by the corresponding changes in the yield of the national market.
Random units $\varepsilon_{g}{ }^{\text {and }} \varepsilon_{i}$ do not correlate with each other. It should be noted that this is an important property, indicating the absence of interaction between diversified global and local risks, which ultimately simplifies the calculation of the numerical characteristics of assets.

First, we determine the mathematical expectation of the return on the asset. For this goal, we substitute expression (5) into (6)

$$
\begin{gathered}
\mathrm{E}\left(r_{i}\right)=\mathrm{E}\left(\alpha_{i}+\beta_{i}\left(\alpha_{g}+\beta_{g} r_{g}+\varepsilon_{g}\right)+\varepsilon_{i}\right) \\
=\alpha_{i}+\beta_{i} \mathrm{E}\left(\alpha_{g}+\beta_{g} r_{g}+\varepsilon_{g}\right) \\
=\alpha_{i}+\beta_{i} \bar{r}_{I} .
\end{gathered}
$$

The result was rather unexpected. From (7) it follows that the profitability of financial assets in the context of globalization depends only on the average profitability in the national market $\bar{r}_{I}$, thereby confirming the validity of the assumption

"everything is included in the price of an asset," including the effect of globalization. So the double-level mechanism reproduced by model (5) - (6) has not changed our idea of the formation of asset returns. In other words, globalization affects only the national market as a whole, i.e. the average market profitability changes under its influence, which is usually measured by the profitability indices.

Absolutely another risk situation. Calculation of the variance $\sigma_{i}^{2}$

$$
\begin{aligned}
& \sigma_{i}^{2}=\mathrm{E}\left(r_{i t}-\bar{r}_{i}\right)^{2} \\
& \begin{array}{c}
=\mathrm{E}\left(\alpha_{i}+\beta_{i} \alpha_{g}+\beta_{i} \beta_{g} r_{g}+\beta_{i} \varepsilon_{g}+\varepsilon_{i}-\alpha_{i}-\beta_{i} \alpha_{g}-\beta_{i} \beta_{g} \bar{r}_{g}\right)^{2} \\
\quad=\beta_{i}^{2} \beta_{g}^{2} \sigma_{g}^{2}+\beta_{i}^{2} \sigma_{\varepsilon_{g}}^{2}+\sigma_{\varepsilon_{i}}^{2},
\end{array}
\end{aligned}
$$

results in structured risk. Moreover, there are not two components in a structured representation, like Sharp, but three: the global risk component in the $i$-th asset $\beta_{i}^{2} \beta_{g}^{2} \sigma_{g}^{2}$; national risk component in $i$-th asset $\beta_{i}^{2} \sigma_{\varepsilon_{g}}^{2}$; asset's own risk $\sigma_{\varepsilon_{i}}^{2}$.

The structured representation of variance allows us to conclude that the effects of globalization must be taken into account when modeling portfolio decisions. Otherwise, the main characteristics of the portfolio of investments may become distorted.

\section{DOUBLE-LEVEL MODELING OF PROFITABILITY IN PORTFOLIO ANALYSIS}

To investigate the details of the formation of the numerical characteristics of the portfolio, we simplify the situation. To do this, leaving the opportunity for generalization, we consider a portfolio of two assets. Assuming that the double-level mechanism for the formation of profitability is in force, we write the formula in accordance with the logic of this mechanism for determining portfolio profitability.

$$
\mathrm{E}\left(r_{p}\right)=\mathrm{E}\left(w_{1} r_{1}+w_{2} r_{2}\right)
$$




$$
\begin{aligned}
& =w_{1}\left(\alpha_{1}+\beta_{1} \bar{r}_{I}\right)+w_{2}\left(\alpha_{2}+\beta_{2} \bar{r}_{I}\right) \\
& =w_{1} \alpha_{1}+w_{2} \alpha_{2}+\bar{r}_{I}\left(w_{1} \beta_{1}+w_{2} \beta_{2}\right) \\
& =w_{1} \alpha_{1}+w_{2} \alpha_{2}+w_{3} \bar{r}_{I} \text {. }
\end{aligned}
$$

The result was expected. In this formula, as in the Sharp model, there is portfolio beta $w_{3}=w_{1} \beta_{1}+w_{2} \beta_{2}$.

Portfolio return is formed from own return on assets and average weighted return on the market. Consequently, globalization does not affect directly to the portfolio returns. Its influence is carried out indirectly, through changes in the stock market under its influence.

For the dispersion of the portfolio, and therefore for risk, the situation is different. Using the usual definition of dispersion, we will write its formula for a portfolio of two assets

$$
\begin{aligned}
\sigma_{p}^{2}= & \mathrm{E}\left[\left(w_{1} r_{1}+w_{2} r_{2}-w_{1} \bar{r}_{1}+w_{2} \bar{r}_{2}\right)^{2}\right] \\
& =w_{1}^{2} \sigma_{1}^{2}+w_{2}^{2} \sigma_{2}^{2}+w_{1} w_{2} \sigma_{12}
\end{aligned}
$$

The formula for the asset's dispersion was obtained above, therefore, we consider only the formula for determining of covariance $\sigma_{12}$. Using the rule for calculating covariance and considering that

$$
\mathrm{E}\left(\varepsilon_{1} \varepsilon_{2}\right)=0, \quad \mathrm{E}\left(\varepsilon_{1} \varepsilon_{g}\right)=0, \quad \mathrm{E}\left(\varepsilon_{2} \varepsilon_{g}\right)=0,
$$

we write the formula for covariance

$$
\sigma_{12}=\mathrm{E}\left[\left(r_{1}-\bar{r}_{1}\right)\left(r_{2}-\bar{r}_{2}\right)\right]
$$

$=\mathrm{E}\left[\left(\beta_{1} \beta_{g}\left(r_{g}-\bar{r}_{g}\right)+\beta_{1} \varepsilon_{g}+\varepsilon_{1}\right)\left(\beta_{2} \beta_{g}\left(r_{g}-\bar{r}_{g}\right)+\beta_{2} \varepsilon_{g}+\varepsilon_{2}\right)\right]$

$$
=\beta_{1} \beta_{2} \beta_{g}^{2} \sigma_{g}^{2}+\beta_{1} \beta_{2} \sigma_{\varepsilon_{g}}^{2}
$$

If we substitute expressions (8) and (11) in (10), we obtain a formula for calculating portfolio dispersion

$$
\begin{gathered}
\sigma_{p}^{2}=w_{1}^{2}\left(\beta_{g}^{2} \beta_{1}^{2} \sigma_{g}^{2}+\beta_{1}^{2} \sigma_{\varepsilon_{g}}^{2}+\sigma_{\varepsilon_{1}}^{2}\right) \\
+w_{2}^{2}\left(\beta_{g}^{2} \beta_{2}^{2} \sigma_{g}^{2}+\beta_{2}^{2} \sigma_{\varepsilon_{g}}^{2}+\sigma_{\varepsilon_{2}}^{2}\right) \\
+w_{1} \mathrm{w}_{2}\left(\beta_{1} \beta_{2} \beta_{g}^{2} \sigma_{g}^{2}+\beta_{1} \beta_{2} \sigma_{\varepsilon_{g}}^{2}\right)
\end{gathered}
$$

After simple transformations of the final formula (12), we can rewrite the dispersion of the portfolio in the form

$$
\begin{gathered}
\sigma_{p}^{2}=w_{1}^{2} \sigma_{\varepsilon_{1}}^{2}+w_{2}^{2} \sigma_{\varepsilon_{2}}^{2} \\
+\beta_{g}^{2} \sigma_{g}^{2}\left(w_{1}^{2} \beta_{1}^{2}+w_{1} w_{2} \beta_{1} \beta_{2}+w_{2}^{2} \beta_{2}^{2}\right) \\
+\sigma_{\varepsilon_{g}}^{2}\left(w_{1}^{2} \beta_{1}^{2}+w_{1} w_{2} \beta_{1} \beta_{2}+w_{2}^{2} \beta_{2}^{2}\right) \\
=w_{1}^{2} \sigma_{\varepsilon_{1}}^{2}+w_{2}^{2} \sigma_{\varepsilon_{2}}^{2}+\left(\sigma_{\varepsilon_{g}}^{2}+\beta_{g}^{2} \sigma_{g}^{2}\right)\left(w_{1} \beta_{1}+w_{2} \beta_{2}\right)^{2} \\
=w_{1}^{2} \sigma_{\varepsilon_{1}}^{2}+w_{2}^{2} \sigma_{\varepsilon_{2}}^{2}+w_{3}^{2}\left(\sigma_{\varepsilon_{g}}^{2}+\beta_{g}^{2} \sigma_{g}^{2}\right)
\end{gathered}
$$

In the portfolio dispersion, which represented by formula (13), there is a dispersion of the main component $\sigma_{g}^{2}$, which describes the synergistic effect of globalization.

This fact allows us to conclude that globalization directly affects the risks of investment decisions. The final formula allows to understand how the Sharp diagonal model differs from its modified version, which takes into account the effect of globalization. As follows from (13), the main difference in the minimized criterion. If Sharp's last element of the diagonal matrix is the variance of the index $\sigma_{T}^{2}$, which characterizes the volatility of the national market, so in a modified version it is the sum of two dispersions. The first term in this sum is the residual dispersion obtained by modeling the dependence of the index on globalization $\sigma_{\varepsilon_{g}}^{2}$, and the second term $\beta_{g}^{2} \sigma_{g}^{2}$ is the adjusted dispersion of the main component that describes the synergistic effect of globalization.

The return of the portfolio, like an asset's return, also depends on globalization, but this dependence is realized through the market.

This fact indicates that the validity of the thesis "everything is included in the price of an asset" applies to situations when the effect of globalization is taken into account. Moreover, if we assume that globalization has an impact on the return on an asset outside the national market, then the effect of globalization on the return on an asset will be taken into account twice.

The final result can be easily extended to the case when $n$ assets are included in the portfolio. For this case, in accordance with (7), we obtain

$$
\mathrm{E}\left(r_{p}\right)=\sum_{i=1}^{n} w_{i} \alpha_{i}+\left(\sum_{i=1}^{n} w_{i} \beta_{i}\right) \bar{r}_{I}
$$

So, the portfolio return is the sum of its own return on assets, and the average market return distributed by portfolio assets. When we introducing the designations

$$
\alpha_{n+1}=\bar{r}_{I},
$$

$$
w_{n+1}=\sum_{i=1}^{n} w_{i} \beta_{i}
$$

the formula of general portfolio return is simplified

$$
\mathrm{E}\left(r_{p}\right)=\sum_{i=1}^{n+1} w_{i} \alpha_{i}
$$

In this case, the dispersion is determined by the formula

$$
\sigma_{p}^{2}=\sum_{i=1}^{n} w_{i}^{2} \sigma_{\varepsilon_{i}}^{2}+\left(\sum_{i=1}^{n} w_{i} \beta_{i}\right)^{2}\left(\sigma_{\varepsilon_{g}}^{2}+\beta_{g}^{2} \sigma_{g}^{2}\right) \text {, }
$$

with three components. The first component is that part of the risk that is generated by assets, the second component is that part of the risk that is formed by the national market and, finally, the third component is taken into account by the impact of globalization. 
Using determinations

$$
\begin{gathered}
\sigma_{\varepsilon_{n+1}}^{2}=\left(\sigma_{\varepsilon_{g}}^{2}+\beta_{g}^{2} \sigma_{g}^{2}\right) \\
w_{n+1}^{2}=\left(\sum_{i=1}^{n} w_{i} \beta_{i}\right)^{2}
\end{gathered}
$$

The formula (16) can be written in a compact form

$$
\sigma_{p}^{2}=\sum_{i=1}^{n+1} w_{i}^{2} \sigma_{\varepsilon_{i}}^{2}
$$

At the formal level, if to use formulas (15) and (17) to construct the Sharpe model (1) - (4) it will remain unchanged, but portfolio decisions, which obtained without taking into account the effects of globalization and with this effects will visibly differ from each other.

The question arises about the completeness of the description of the effects of globalization using only one main component. Of course, the usage of all the main components should provide a complete description, but there may be a problem with the construction of a regression model with statistically significant coefficients for the main components. At the same time, the situation with the indication of the effects of globalization is not interesting for all, but for several main components, the diagonal model of portfolio investment allowed the usage of only one-factor regression models, because of specifics of the plotting. The case of orthogonal factors was not considered, but the main components with their orthogonality may well be able to overcome the problems that arise during the formation of the optimization model.

That's why, we consider the case when the econometric modeling of the profitability of the national market showed that the two main components turned out to be statistically significant. To simplify the notation of the regression equation itself and all the expressions associated with it, we assume that these are the first $r_{1 g}$ and second $r_{2 g}$ are main components.

In this case, the model of the double-level mechanism for generating of profitability is written as

$$
r_{I}=\alpha_{g}+\beta_{1 g} r_{1 g}+\beta_{2 g} r_{2 g}+\varepsilon_{g}
$$

$$
r_{i}=\alpha_{i}+\beta_{i} r_{I}+\varepsilon_{i}
$$

Then the mathematical expectation of the return on the asset can be written as

$$
\begin{aligned}
& \mathrm{E}\left(r_{i}\right)=\mathrm{E}\left(\alpha_{i}+\beta_{i}\left(\alpha_{g}+\beta_{1 g} r_{1 g}+\beta_{2} r_{2 g}+\varepsilon_{g}\right)+\varepsilon_{i}\right) \\
& =\alpha_{i}+\beta_{i} \mathrm{E}\left(\alpha_{g}+\beta_{1 g} r_{1 g}+\beta_{2 g} r_{2 g}+\varepsilon_{g}\right) \\
& =\alpha_{i}+\beta_{i} \bar{r}_{I}
\end{aligned}
$$

demonstrating their independence from globalization and the number of main components included in the model.

If we will take into account statistical independence of the main components than the disperse of the asset, can be represented as

$$
\sigma_{i}^{2}=\mathrm{E}\left(r_{i}-\bar{r}_{i}\right)^{2}
$$

$$
=\sigma_{\varepsilon_{i}}^{2}+\beta_{i}^{2} \sigma_{\varepsilon_{g}}^{2}+\beta_{i}^{2}\left(\beta_{1 g}^{2} \sigma_{g_{1}}^{2}+\beta_{2 g}^{2} \sigma_{g_{2}}^{2}\right)
$$

The changes that occurred with the dispersion of the asset were expected. Its component, which characterizes the contribution of globalization to asset volatility, is formed depending on the dispersions of the two main components. Normally, the accuracy of the risk appreciates is estimated using the two main components that describe the effect of globalization `higher than the obtained accuracy when using one main component.

The final formula is easily generalized to the case of $m$ principal components

$$
\begin{aligned}
\sigma_{i}^{2}= & \mathrm{E}\left(r_{i}-\overline{r_{i}}\right)^{2} \\
& =\sigma_{\varepsilon_{i}}^{2}+\beta_{i}^{2} \sigma_{\varepsilon_{g}}^{2}+\beta_{i}^{2} \sum_{k=1}^{m} \beta_{g_{k}}^{2} \sigma_{g_{k}}^{2}
\end{aligned}
$$

The return on the asset and the return on the portfolio in this case are determined without changes in accordance with (7) and (14). That's why, it makes sense to get only the formula according to which dispersion of the portfolio is calculated in the context of globalization for cases when the effect of globalization is described by several main components. From the definition of dispersion follows

$$
\begin{array}{r}
\sigma_{p}^{2}=\mathrm{E}\left[\left(\sum_{i=1}^{n} w_{i} r_{i}-\sum_{i=1}^{n} w_{i} \bar{r}_{i}\right)^{2}\right] \\
=\sum_{i=1}^{n} w_{i}^{2} \sigma_{i}^{2}+\sum_{i=1}^{n} \sum_{j=1}^{n} w_{i} w_{j} \sigma_{i j},
\end{array}
$$

In the obtained representation of dispersion, the expression for $\sigma_{i j}$ covariance is not known. By definition

$$
\begin{gathered}
\sigma_{i j}=\mathrm{E}\left[\left(r_{i}-\bar{r}_{i}\right)\left(r_{j}-\bar{r}_{j}\right)\right] \\
=\mathrm{E}\left[\left(\beta_{i} \sum_{k=1}^{m} \beta_{g_{k}}\left(r_{g_{k}}-\bar{r}_{g_{k}}\right)+\varepsilon_{g}\right) \times\left(\beta_{j} \sum_{k=1}^{m} \beta_{g_{k}}\left(r_{g_{k}}-\bar{r}_{g_{k}}\right)+\varepsilon_{g}\right)\right] \\
=\beta_{i} \beta_{j} \sum_{k=1}^{m}\left(\beta_{g_{k}}^{2} \sigma_{g_{k}}^{2}+\sigma_{\varepsilon_{g}}^{2}\right)
\end{gathered}
$$

Substituting formulas (22) and (24) into (23), after the transformation, we obtain the portfolio dispersion for the case when the globalization effect is described by $m$ main components

$$
\begin{gathered}
\sigma_{p}^{2}=\sum_{i=1}^{n} w_{i}^{2}\left(\sigma_{\varepsilon_{i}}^{2}+\beta_{i}^{2} \sigma_{\varepsilon_{g}}^{2}+\beta_{i}^{2} \sum_{k=1}^{m} \beta_{g_{k}}^{2} \sigma_{g_{k}}^{2}\right) \\
+\sum_{i=1}^{n} \sum_{j=1}^{n} w_{i} w_{j} \beta_{i} \beta_{j} \sigma_{\varepsilon_{g}}^{2}+\sum_{i=1}^{n} \sum_{j=1}^{n} w_{i} w_{j} \beta_{i} \beta_{j}\left(\sum_{k=1}^{m} \beta_{g_{k}}^{2} \sigma_{g_{k}}^{2}\right) \\
=\sum_{i=1}^{n} w_{i}^{2} \sigma_{\varepsilon_{i}}^{2}+\left(\sum_{i=1}^{n} w_{i} \beta_{i}\right)^{2} \sigma_{\varepsilon_{g}}^{2}+\left(\sum_{i=1}^{n} w_{i} \beta_{i}\right)^{2} \sum_{k=1}^{m} \beta_{g_{k}}^{2} \sigma_{g_{k}}^{2} \\
\begin{array}{l}
\text { Published By: } \\
\text { Blue Eyes Intelligence Engineering } \\
\text { \& Sciences Publication }
\end{array}
\end{gathered}
$$


So, by this way, it turned out that there are three components in the dispersion of the portfolio, as in the dispersion of the asset. The first component characterizes the weighted sum of disperses of assets included in the portfolio, the second component indicates the volatility of the national market in the context of globalization, and finally the third component indicates the sum of variances of the main components that describe the effects of globalization. Therefore, the risk when the effects of globalization are taken into account differs in structure from the risk structure used in the Sharp model.

If we introduce notations similar to those used in (17), then the dispersion of the portfolio can be written in a more compact form

$$
\sigma_{p}^{2}=\sum_{i=1}^{n} w_{i}^{2} \sigma_{\varepsilon_{i}}^{2}+\left(\sum_{i=1}^{n} w_{i} \beta_{i}\right)^{2}\left(\sigma_{\varepsilon_{g}}^{2}+\sum_{k=1}^{m} \beta_{g_{k}}^{2} \sigma_{g_{k}}^{2}\right)=\sum_{i=1}^{n+1} w_{i}^{2} \sigma_{\varepsilon_{i}}^{2} .
$$

Thus, in general case, the presentation of the numerical characteristics of the investments portfolio is similar to those in the particular case, when using only one main component. Therefore, when forming a portfolio investment model, which takes into account the effects of globalization, reflected by the $m$ main components, the value of the last element of the diagonal matrix is calculated using expression (26).

The practical application of the portfolio investment model, which takes into account the effects of globalization, makes sense in cases where the reality of the assumption of a double-level mechanism for generating profitability is confirmed by an adequate model of its reproduction. The adequacy of the model of two regression equations is applied as the adequacy of each of the equations of the system.

\section{THE RESULTS OF EMPIRICAL EXPLORATIONS}

The validity of abovementioned theoretical results, which describe the basis for modeling of investment solutions in the Russian stock market in the context of globalization, have been confirmed by empirical studies. To conduct the calculation experiments with a double-level model, were selected 7 of the most traded stocks and 6, excluding RTS, of fairly popular indices. Their descriptions are given in the tables with the calculation results.

Following the logic of constructing a diagonal model of portfolio investment on the basis of the proposed approach, all the necessary regression dependencies were built. The adequacy of all models was the guarantee of a plausible reproduction of the real situation. A comparative analysis with the classical version of the Sharpe model, as well as various variants among themselves, was carried out on the data of the post-pre-emptive period of 5 observations. The data of the post-pre-emptive period were not used in the construction of regression models, which allowed, in our opinion, to confirm the high reliability of the obtained results.

Table 1 shows the off-center main components constructed for foreign indices, as well as their dispersions and average values.

The given dispersion values show that the first two components describe $87 \%$ of the changes that took place on foreign stock markets during the studied period of time. If you take into account the three main components, then this percentage increases to $95 \%$. Because of this, the use of a regression model for all the main components loses its usefulness. In addition, we will note that the inclusion of components with a low level of dispersion in the model may ultimately lead to increase in the random component of the investment decision.

Table 1 - Major components of international stock indices

\begin{tabular}{|c|c|c|c|c|c|c|}
\hline \multirow{2}{*}{ Indices } & \multicolumn{7}{|c|}{ Major components } \\
\cline { 2 - 7 } & $1-я$ & $2-я$ & $3-я$ & $4-я$ & 5 -я & 6-я \\
\hline DOW JONES & 0,34729 & 0,13963 & 0,18874 & $-0,89960$ & 0,07548 & $-0,09645$ \\
\hline SHANGHAI & 0,20607 & $-0,96531$ & 0,15526 & $-0,03888$ & $-0,00816$ & 0,00457 \\
\hline N225JAP & 0,21484 & $-0,10382$ & $-0,96171$ & $-0,13145$ & 0,02795 & $-0,01079$ \\
\hline DAX & 0,55676 & 0,11810 & 0,09050 & 0,27436 & 0,69265 & 0,33592 \\
\hline CAC40 & 0,54863 & 0,11473 & 0,07013 & 0,30290 & $-0,23538$ & $-0,73059$ \\
\hline FUTSEE-100 & 0,42401 & 0,10386 & 0,04767 & 0,07013 & $-0,67697$ & 0,58647 \\
\hline & 14,06829 & 9,11020 & 2,20811 & 0,76699 & 0,28010 & 0,19698 \\
\cline { 2 - 6 } & \multicolumn{7}{|c|}{ The average values of major components } \\
\cline { 2 - 7 } & $-0,47938$ & 0,02749 & 0,03004 & $-0,05354$ & $-0,04095$ & 0,06322 \\
\cline { 2 - 7 }
\end{tabular}

When plotting regression dependencies, it is impossible to exclude a situation when not all the main components can be statistically significant. Moreover, the logic according to which more than one statistically significant component may appear in a regression model is not entirely clear. Obviously, such a case contradicts the fact that the main components are statistically independent from each other. So anyway, two similar orthogonal factors may turn out to be statistically significant in a regression dependence in case if their statistical significance, provided that the indicator is moderately correlated, is ensured by a sufficiently large selective totality. Therefore, to get a complete picture of the usage of 
the main components to justify the investment decisions in the context of globalization, it is necessary to consider all possible options.
The results of modeling of investment portfolios using regression models for the main components in various combinations are shown in table 2 .

Table 2 - Portfolio solutions in dependence on components quantity

\begin{tabular}{|c|r|r|r|r|r|r|r|}
\hline \multirow{2}{*}{ Assets } & \multicolumn{7}{|c|}{ Portfolios } \\
\cline { 2 - 9 } & \multicolumn{1}{|c|}{1 гл.к. } & 1,2 гл.к. & \multicolumn{1}{c|}{$1-3$ гл.к. } & \multicolumn{1}{c|}{$1-4$ гл.к. } & $1-5$ гл.к. & \multicolumn{1}{c|}{1 -6 гл.к. } & \multicolumn{1}{c|}{ РТС } \\
\hline Sberbank & $-0,03523$ & $-0,03478$ & $-0,03443$ & $-0,03661$ & $-0,11173$ & $-0,17078$ & $-0,28214$ \\
\hline Rosneft & 0,24378 & 0,24417 & 0,24448 & 0,24257 & 0,17672 & 0,12495 & 0,02733 \\
\hline NLMK & $-0,16740$ & $-0,16677$ & $-0,16627$ & $-0,16936$ & $-0,27614$ & $-0,36008$ & $-0,51838$ \\
\hline MMK & $-0,32898$ & $-0,32955$ & $-0,32999$ & $-0,32723$ & $-0,23180$ & $-0,15678$ & $-0,01531$ \\
\hline Lukoil & 0,66011 & 0,65968 & 0,65935 & 0,66142 & 0,73280 & 0,78891 & 0,89473 \\
\hline Nornikel & 0,40217 & 0,40197 & 0,40182 & 0,40278 & 0,43604 & 0,46219 & 0,51151 \\
\hline Gazprom & 0,22555 & 0,22527 & 0,22504 & 0,22642 & 0,27410 & 0,31159 & 0,38227 \\
\hline & \multicolumn{7}{|c|}{ The risks } \\
\cline { 2 - 9 } & 1,44987 & 1,44831 & 1,44709 & 1,45471 & 1,69753 & 1,86637 & 2,14897 \\
\hline & 1,61593 & 1,61679 & 1,61746 & 1,61326 & 1,46798 & 1,35378 & 1,13841 \\
\hline
\end{tabular}

From the abovementioned results, it follows: when the first three components that account for $95 \%$ of the volatility of foreign markets are sequentially included in the model, there was a slight increase in expected return with a slight decrease in risk. The inclusion of the 4-th main component with a $3 \%$ contribution to the overall volatility in the model led to a turning point, when another trend become, according to which the portfolio risk began to increase slightly, and profitability slightly decrease. The inclusion of the 5th and 6th components in the model has strengthened this trend. After the inclusion of this components in the model, the risk has increased markedly, and the expected return decreased. From the obtained results it follows that in the last major components that have an insignificant contribution to the overall volatility of global processes, are reproduce a random (noise) component, which inclusion into the model makes its characteristics worse.

It is also important to note that portfolios constructed taking into account the effects of globalization in terms of their main characteristics (risk, profitability) are more preferable to a portfolio constructed in accordance with the diagram of the Sharp diagonal model (last column of table 2).

\section{CONCLUSION}

The obtained results of empirical explorations shown that a double-level model that describes the mechanism of globalization influence on the national market is a useful tool, which usage increases the efficiency of the investment decisions making.

The double-level description also allows us to understand the specifics of the mechanism of the influence of globalization on the assets of the national market. In accordance with this specificity, the yield of an asset is formed by the national market only, and the risk substantially depends on the volatility of global processes.

This result does not contradict the postulates of modern financial theory, and also fits well with risk theory, which states that risk is an individual phenomenon. The individuality of the Russian stock market is that the risks of investment decisions on thin market largely depend on situations in foreign financial markets.

A double-level model for the formation of profitability of financial assets, in fact, is the development of Sharp's ideas on introducing an econometric approach into the tasks by forming of optimal investment decisions. We must admit that these are the first steps in developing an econometric approach, involving the reproduction of only linear dependencies. The reality of market processes is much more complicated, that, of course, focuses us on further research using the modern potential of econometrics.

\section{REFERENCES}

1. Balyuk I.A. and others, 2018. The impact of globalization on the formation of the Russian financial market. Moscow: KNORUS (in Russian).

2. Burenin, A.N., 2008. Management of securities portfolio. Moscow: NTO Vavilova S.I. (in Russian).

3. Davnis, V.V., Kasatkin, S.E., Ardakov, A.A., 2012. The main components and their application in models of portfolio investment. Sovremennaya e'konomika: problemy' i resheniya [Modern economy: problems and solutions], 7(31): 150-157. (in Russian).

4. Davnis, V.V., Ziroyan, M.A., Tinyakova, V.I., 2017. Markowitzs model on an extended set of investment opportunities. Economic and Social Development. Book of Proceedings. Varazdin Development and Entrepreneurship Agency; Russian State Social University, pp. 394-404.

5. Davnis, V.V., Ziroyan, M.A., Vladyka, M.V., Kamyshanchenko, E.N., Tinyakova ,V.I., 2015. A situational model of investment portfolio. International Business Management, 9(5): 948-954.

6. Demidov V.V., 2007. Methods of optimization of the stock portfolio in the context of globalization. Ekonomicheskiye nauki [Economic Sciences], 4 (29): 55-58. (in Russian).

7. Karyagina, T.V., Lebedeva, M.V., Fetisov, V.A., 2015. Optimal Portfolio solutions in the context of globalization. Innovacii i investicii [Innovation and investment], 7: 91-95. (in Russian).

8. Lintner, J., 1965. Security Prices Risk and Maximal Glans from Diversification. Journal of Finance. December: 587-616. 
9. Lintner, J., 1965. The Valuation of Risk Assets and the Selection of Risk Invest Mends in Stock Portfolios and Capitals Budgets. Review of Economics and Statistics. February: 13-37.

10. Markowitz, H.M., 1952. Portfolio Selection. Journal of Finance, 7(1): 77-91.

11. Roll, R., 1977. A Critique of Asset Pricing Theory's Tests. Journal of Finance and Economics. March: 129-176.

12. Sharpe W., 1970. Portfolio Theory and Capital Markets. N.Y. McGraw-Hill, 1970.

13. Sharpe W.F., 1964. Capital Asset Price: A Theory of Market Equilibrium Under Conditions of Risk. Journal of Finance, 19(3): 425-442.

14. Sharpe, W.F., 1963. A Simplified Model for Portfolio Analysis. Management Science, 9(2): 277-293.

15. Shiryaev, V.I., 2009. Models of financial markets. Optimal portfolios financial and risk management. Moscow: Librokom (in Russian).

16. Tinyakova, V.I., Maloletko, A.N., Kaurova, O.V., Vinogradova, M.V., Larionova, A.A., 2017. Model of evaluation of influence of globalization on the national stock market. Contributions to Economics. Issue 9783319552569: 261-272.

17. Tinyakova, V.I., Miroshnikov, E.V., 2019. Adaptive modeling of forecast estimates of the main components of stock indexes in portfolio investment problems. Vestnik Altajskoj akademii e'konomiki i prava [Bulletin of the Altai Academy of Economics and Law], 2: 152-161. (in Russian).

18. Tobin, J., 1958. Liquidity Preferences as a Behavior Toward Risk. Review Economic Studies, 25 (6): 65-68.

19. Tobin, J., 1965. The Theory of Portfolio Selection. Theory of Interest Rates / Ed. by F.H. Hahn, F.P.R. Brechling. London: MacMillan: 3-5.

20. Yanovsky, L.P., Vladykin, S.N., 2009. Portfolio selection taking into account the horizon of investment. Finansy i kredit [Finance and Credit] 29 (365): 12-18. (in Russian). 